\title{
Limited range correlations, when modulated by firing rate, can substantially improve neural population coding
}

\author{
Joel Zylberberg ${ }^{1 *}$, Jon Cafaro ${ }^{2}$, Maxwell Turner ${ }^{3}$, Fred Rieke ${ }^{3,4}$, Eric Shea-Brown ${ }^{1}$ \\ From 24th Annual Computational Neuroscience Meeting: CNS*2015 \\ Prague, Czech Republic. 18-23 July 2015
}

Neural activities are unreliable indicators of features of the external world [1], and an open question is how our nervous systems function robustly in the presence of this noise. One possibility arises from the observation that variability is often correlated between neurons [2], leading to the important theoretical question of when and how noise correlations affect neural population codes. Much work has investigated this issue, leading to impressive insights about how the relationship between the statistical structures of signals vs noise affects neural population coding. Despite this progress, an important issue has been largely overlooked by the field: that of firing-rate-dependent correlations. Notably, the same pair of neurons can display different noise correlations in response to different stimuli; those correlations coefficients typically increase with increases in the neurons' firing rates $[2,3]$.

In this paper, we investigate the role of so-called "limited range" correlations on population codes, either in the presence, or the absence of rate-modulation of the correlation coefficients. Limited-range correlations are frequentlyobserved population-wide correlation structures in which cells with similar tuning curves have positive noise correlations, and the correlations decrease with decreasing tuning curve similarity $[2,4]$. These patterns of noise correlation are typically harmful to population coding [5] (yielding worse population coding performance than would be obtained with the same tuning curves and noise variances for all cells, but no noise correlations); these effects are somewhat dependent on the degree of heterogeneity in the population's tuning curves $[6,7]$.

\footnotetext{
*Correspondence: joelzy@uw.edu

'Department of Applied Mathematics, University of Washington, Seattle, WA 98195, USA

Full list of author information is available at the end of the article
}

Experimentally reported noise correlations are usually averaged over stimuli, thereby masking any stimulus dependence. Herein, we will demonstrate that, when correlation coefficients increase with the product of mean neural firing rates (as in $[2,3]$ ), the stimulus-averaged correlation coefficients will display limited-range structure. When the rate dependence of these correlations is ignored, those correlations appear to be quite harmful to the population code, in accordance with previous theoretical work [5]. Surprisingly, when the rate dependence is taken into account, the correlations can yield much better population coding than would be obtained in the presence of uncorrelated noise. These effects persist for either homogeneous or heterogeneous sets of neural tuning curves. One prior study [8] also found that ratedependent correlations can have very different impacts on population codes than can rate-independent ones, but did not make the connection between firing-ratedependent correlations and the frequently observed limited-range correlation structure. Overall, our results emphasize that, for understanding the impact of limitedrange correlations on neural population coding, the firing-rate dependence of those correlations is a potentially important consideration. Thus, it is important to report not only stimulus-averaged correlation coefficients, but also the relationship between those correlation coefficients and the neural firing rates.

\footnotetext{
Authors' details

${ }^{1}$ Department of Applied Mathematics, University of Washington, Seattle, WA 98195, USA. '2Department of Biology, Duke University, Durham, NC 27708, USA. ${ }^{3}$ Department of Physiology and Biophysics, University of Washington, Seattle, WA 98195, USA. ${ }^{4}$ Howard Hughes Medical Institute, University of Washington, Seattle, WA 98195, USA.
}

Published: 18 December 2015 


\section{References}

1. Faisal AA, Selen LPJ, Wolpert DM: Noise in the nervous system. Nat Rev Neurosci 2008, 9(4):292-303.

2. Cohen MR, Kohn AK: Measuring and interpreting neuronal correlations. Nat Neurosci 2011, 14(7):811-819.

3. de la Rocha J, Doiron B, Shea-Brown E, Josic K, Reyes A: Correlation between neural spike trains increases with firing rate. Nature 2007, 448:802-806.

4. Zohary E, Shadlen MN, Newsome WT: Correlated neuronal discharge rate and its implications for psychophysical performance. Nature 1994, 370(6485):140-143.

5. Averbeck BB, Latham PE, Pouget A: Neural correlations, population coding and computation. Nat Rev Neurosci 2006, 7(5):358-366.

6. Ecker AS, Berens $\mathrm{P}$, Tolias AS, Bethge M: The effect of noise correlations in populations of diversely tuned neurons. J Neurosci 2011, 31(40):14272-14283.

7. Shamir M, Sompolinsky H: Implications of neuronal diversity on population coding. Neural Comput 2006, 18(8):1951-1986.

8. Josic K, Shea-Brown E, Doiron B, de la Rocha J: Stimulus-dependent correlations and population codes. Neural Comput 2009, 21(10):2774-2804.

doi:10.1186/1471-2202-16-S1-016

Cite this article as: Zylberberg et al:: Limited range correlations, when modulated by firing rate, can substantially improve neural population coding. BMC Neuroscience 2015 16(Suppl 1):016.

\section{Submit your next manuscript to BioMed Central} and take full advantage of:

- Convenient online submission

- Thorough peer review

- No space constraints or color figure charges

- Immediate publication on acceptance

- Inclusion in PubMed, CAS, Scopus and Google Scholar

- Research which is freely available for redistribution

Submit your manuscript at www.biomedcentral.com/submit 